\title{
НЕЙРОЭНДОКРИННЫЕ
}

\section{АСПЕКТЫ СТАНОВЛЕНИЯ МЕНСТРУАЛЬНОЙ ФУНКЦИИ У ДЕВОЧЕК-ПОДРОСТКОВ}

\section{Н.Ф. ЕФИМЕНКО \\ к.б.н., заведующий кафедрой лабораторной диагностики и общей патологии Запорожской медицинской академии последипломного образования \\ В.Н. ПЛОТНИКОВА к.мед.Н., доцент кафедры акушерства и гинекологии Запорожской медицинской академии последипломного образования}

\section{Г.И. РЕЗНИЧЕНКО}

д.М.н., просрессор кафедры акушерства и гинекологии Запорожской медицинской академии последипломного образования
O дной из важнейших проблем современной медицины является раннее выявление нарушений становления менструальной функции у девочек-подростков. В силутого, что механизм регуляции репродуктивной системы в этот период окончательно не сорормирован, система отличается повышенной чувствительностью к действию неблагоприятных фракторов внешней и внутренней среды организма. Поэтому юношеский период можно рассматривать как период риска возникновения нарушений функции репродуктивной системы [4]. Этот период во многом определяет репродуктивное здоровье будущей женщины-матери, поэтому решение данной проблемы имеет не только медицинское, но и социальное значение.

Как известно, в стимуляции фризического и полового развития женского организма участвуют многие гормоны и биологически активные вещества. Современные представления о сложных процессах регуляции полового созревания девочек пополняются все новыми данными о роли нервных и гуморальных фракторов в этом процессе [2, 8]. По мнению ряда авторов, запуск процесса полового созревания зависит от чувствительности гипоталамических центров к половым гормонам, регулирующее воздействие которых реализуется посредством гормонов эпифиза - мелатонина и серотонина [8]. Как известно, у зародышей и новорожденных млекопитающих мелатонин помогает запрограммировать циркадные ритмы и определяет время начала и окончания полового созревания. У человека этот гормон начинает продуцироваться эпифизом вскоре после рождения, его концентрация постепенно повышается, достигая максимума в возрасте 7 лет $[1,6,7]$. Резкое снижение уровня гормона в период полового созревания, продолжающееся в среднем до 20-летнего возраста, способствует активации гонадотропной функции гипофиза, выработке фолликулостимулирующего (ФСГ) и лютеинизирующего (ЛГ) гормонов, которые оказывают стимулирующее влияние на развитие фолликулов и биосинтез половых гормонов в гонадах. В динамике менструального цикла минимальный уровень мелатонина наблюдается во время овуляции и совпадает с овуляционным пиком ЛГ, а максимум содержания мелатонина приходится на период менструального кровотечения на фоне низкого уровня ЛГ [7]. Этот механизм обеспечивает включение репродуктивной функции человека.

Цель настоящего исследования состояла в изучении особенностей взаимосвязи между мелатонином, серотонином, гонадотропными и половыми гормонами в процессе становления менструальной функции у девочек-подростков г. Запорожья крупного центра металлургической промышленности и энергетики с неблагоприятной экологической ситуацией.

\section{МАТЕРИАЛЫ И МЕТОДЫ ИССЛЕДОВАНИЯ}

В исследование были включены 53 практически здоровые девочки без отклонений фризического развития в возрасте 9-17 лет, рандомизированные на три группы. В первую группу вошли 12 неменструирующих девочек 9-12 лет; во вторую - 23 пациентки 13-17 лет с нерегулярными менструациями (через 2-5 мес), менструирующие нерегулярно на протяжении от 6 мес до 1 года; в третью - 18 лиц в возрасте 13-17 лет с установившимся регулярным менструальным циклом, менструирующие на протяжении 2-3 лет.

Все пациентки были обследованы клинически, с учетом физического и полового развития, состояния молочных желез, с использованием тестов фрункциональной диагностики. Лабораторное обследование включало определение уровней в крови: эстрадиола, тестостерона, пролактина, ЛГ и ФСГ - радиоиммунологическим методом, а также изучение содержания серотонина и мелатонина в крови, экскреции дофамина с мочой - спектрофлуориметрическими методами. Обследование проводили на 5-7-й день менструального цикла при регулярных месячных или дважды с интервалом в 7 дней при отсутствии таковых. Результаты исследования обрабатывали статистически с использованием t-критерия Стьюдента.

\section{РЕЗУЛЬТАТЫ И ИХ ОБСУЖДЕНИЕ}

Полученные результаты гормонального обследования представлены в таблице.

Как следует из приведенных данных, у неменструирующих девочек первой группы (средний возраст 10,7 \pm 0,4 года) уровень ЛГ и ФСГ был низким, составлял в среднем 4,32 \pm 0,51 и 4,17 \pm 0,42 мМЕ/мл соответственно, а средняя величина секреции пролактина - 292,2 \pm 56,8 мМЕ/л. У всех пациенток этой группы выявлено низкое содержание эстрадиола, в среднем 72,7 \pm 6,7 пмоль/л. При этом среднее содержание мелатонина было равно 0,74 \pm 0,02 нмоль/л, а средняя величина концентрации серотонина в крови составила $0,37 \pm 0,02$ мкмоль/л. Экскреция дофрамина соответствовала таковой для данной возрастной группы и равнялась 82,0 \pm 8,5 мкг/сут. Полученные результаты подтверждают сложившееся мнение о том, что в препубертатный период гипоталамо-гипофизарная система обладает высоким порогом чувствительности и не реагирует на низкий уровень половых гормонов.

У подростков второй группы с нерегулярными менструациями (через 2-5 мес), средний возраст которых составлял 14,55 0,33 года, наблюдалась некоторая тенденция к повышению уровня гонадотропных гормонов по сравнению с девочками первой группы. Однако в большей степени это касалось ЛГ, секреция которого находилась в пределах 4,61 \pm 0,48 мMЕ/мл. В то же время уровень ФСГ практически не отличался от такового у неменструирующих девочек и составил в среднем 4,20 \pm 0,34 мME/мл. У пациенток второй группы был отмечен высокий уровень пролактина, в среднем 522,27 $\pm 53,3$ мMЕ/л, различие с показателем у неменструирующих девочек было статистически достоверным $\left(p_{1}<0,05\right)$. 
Как известно, уровень пролактина отражает сдвиги в нейромедиаторной системе гипоталамуса. В частности, снижение уровня досрамина (медиатора, подавляющего секрецию пролактина) сопровождается повышением уровня пролактина в крови [2]. Это можно объяснить дисрегуляцией нейромедиаторных систем, а именно: низким уровнем дофамина и повышенной продукцией мелатонина и серотонина. Последние известны как пролактин-рилизинг-фракторы, среднее содержание которых у лиц данной группы имело даже некоторую тенденцию к повышению по сравнению с такими показателями у неменструирующих девочек младшего возраста и составило соответственно 0,79 \pm 0,043 нмоль/л и 0,38 \pm 0,016 мкмоль/л.

Учитывая особенности биосинтеза мелатонина, а именно образование его из предшественника - серотонина, мы определяли коэффициент отношения мелатонин/серотонин как показатель интенсивности образования мелатонина. У регулярно менструирующих подростков этот показатель составил 1,75 \pm 0,08, что было принято условно за единицу. У неменструирующих девочек этот показатель был равен 2,0 0 0,06 $(1,14)$, практически таким же он был у пациенток второй группы с нерегулярными менструациями $-2,1 \pm 0,09(1,16)$. Корреляционный анализ показал, что между соотношением мелатонин/серотонин и уровнями ФСГ и ЛГ наблюдалась обратная корреляционная связь средней силы $(r=-0,38 ; r=-0,43 ; p<0,05)$. Эти данные позволяют считать, что запаздывание снижения уровня мелатонина может быть одной из причин задержки становления менструальной функции у девочек. Гиперпролактинемия в свою очередь подавляет синтез и секрецию ЛГ и ФСГ аденогипофизом, вследствие чего снижается биосинтез половых гормонов в яичниках, о чем свидетельствует низкий уровень эстрадиола у девочек данной группы.

У пациенток третьей группы с установившимся менструальным циклом (средний возраст 14,72 \pm 0,29 года) нейроэндокринные взаимоотношения были близки к таковым у взрослых женщин репродуктивного возраста. Так, уровень ЛГ и ФСГ оказался достоверно выше, чем у неменструирующих и нерегулярно менструирующих девочек первой и второй групп и составил в среднем 8,42 \pm 0,77 и 6,21 $\pm 0,42$ мМЕ/мл соответственно $(p<0,01)$. Концентрация пролактина при этом соответствовала уровню гормонов в репродуктивном периоде и равнялась 264,2 $\pm 36,1$ мME/л. Снижение содержания пролактина у пациенток этой группы свидетельствует о нормализации нейроэндокринных взаимоотношений - повышении ингибирующего влияния досрамина на фоне снижения пролактинрилизинг-сракторов (серотонина и мелатонина). Отсутствие или запаздывание снижения уровня мелатонина может быть одной из основных причин расстройства нейроэндокринной регуляции и задержки становления менструальной функции у девочек-подростков. Именно поэтому определение уровня мелатонина может иметь прогностическое значение.

Таким образом, становление менструальной функции у девочек-подростков обусловлено созреванием гипоталамо-гипосризарной системы, связанным со снижением уровня серотонина и особенно мелатонина. Нарушения центральных механизмов регуляции менструальной функции у девочек могут быть следствием хронического стресса, обусловленного высокими фризическими и эмоциональными нагрузками в сочетании с неблагоприятными экологическими условиями жизни в большом промышленном городе и определенной наследственной предрасположенности $[3,4]$. Усиление секреции гормонов коры надпочечников - неизменный спутник любой стрессорной реакции, и некоторое повышение уровня кортизола, отмеченное у девочек с отставанием становления менструальной функции, также может указывать на определенную роль стресса в данном процессе [5]. Так,
ТАБЛИЦА

СОДЕРЖАНИЕ ГОРМОНОВ И МОНОАМИНОВ В КРОВИ ДЕВОЧЕК-ПОДРОСТКОВ $(\mathrm{M} \pm \mathrm{m})$

\begin{tabular}{|c|c|c|c|}
\hline Гормоны & $\begin{array}{c}\text { Первая группа } \\
\mathrm{n}=12\end{array}$ & $\begin{array}{c}\text { Вторая группа } \\
\mathrm{n}=23\end{array}$ & $\begin{array}{c}\text { Третья группа } \\
\text { n }=18\end{array}$ \\
\hline ЛГ, мМЕ/мЛ & $4,32 \pm 0,51$ & $4,61 \pm 0,48$ & $\begin{array}{c}8,42 \pm 0,77 \\
p<0,01^{*} \\
p_{1}<0,01^{*}\end{array}$ \\
\hline ФСГ, мМЕ/мл & $4,17 \pm 0,42$ & $4,20 \pm 0,34$ & $\begin{array}{c}6,21 \pm 0,42 \\
p<0,01^{*} \\
p_{1}<0,01^{*}\end{array}$ \\
\hline Пролактин, мМЕ/л & $292,2 \pm 56,8$ & $\begin{array}{c}522,27 \pm 53,3 \\
p_{3}<0,01^{*} \\
p_{1}<0,05^{*}\end{array}$ & $264,2 \pm 36,1$ \\
\hline Эстрадиол, пмоль/л & $72,7 \pm 6,7$ & $79,6 \pm 13,2$ & $\begin{array}{c}160,6 \pm 20,9 \\
p<0,05^{*} \\
p_{1}<0,05^{*}\end{array}$ \\
\hline $\begin{array}{l}\text { Тестостерон, } \\
\text { нмоль/л }\end{array}$ & $2,1 \pm 0,20$ & $3,2 \pm 0,57$ & $2,59 \pm 0,52$ \\
\hline $\begin{array}{l}\text { Серотонин, } \\
\text { мкмоль/л }\end{array}$ & $0,37 \pm 0,02$ & $\begin{array}{c}0,38 \pm 0,016 \\
p_{3}<0,05^{\star}\end{array}$ & $0,32 \pm 0,02$ \\
\hline $\begin{array}{l}\text { Мелатонин, } \\
\text { нмоль/л }\end{array}$ & $0,74 \pm 0,09$ & $\begin{array}{c}0,79 \pm 0,043 \\
p_{3}<0,01^{*}\end{array}$ & $0,56 \pm 0,09$ \\
\hline Досрамин, мкг/сут & $89,0 \pm 8,5$ & $102,0 \pm 9,7$ & $124,0 \pm 17,7$ \\
\hline Кортизол, нмоль/л & $150,7 \pm 18,7$ & $358,7 \pm 35,7$ & $295,5 \pm 25,1$ \\
\hline $\begin{array}{l}\text { Мелатонин/ } \\
\text { серотонин }\end{array}$ & $2,0 \pm 0,06(1,14)$ & $2,1 \pm 0,1(1,16)$ & $1,75 \pm 0,08(1)$ \\
\hline
\end{tabular}

* p - по сравнению со второй группой; $p^{1}$ - по сравнению с первой группой; $p^{3}$ - по сравнению с третьей группой средняя секреция кортизола у неменструирующих девочек составила 150,7 \pm 18,7 нмоль/л, у регулярно менструирующих $295,5 \pm 19,7$ нмоль/л, а у подростков с отставанием становления менструальной функции - 358,7 $\pm 25,0$ нмоль/л $(p<0,05)$. Антистрессорное повышение уровня мелатонина, коррелирующее с уровнем кортизола, вначале выполняет определенную защитную функцию, однако при хроническом стрессе может стать причиной задержки формирования ритмической активности гипоталамо-гипофизарно-гонадной системы. В этой связи уменьшение стрессовых воздействий у девочек-подростков и девушек в сочетании с ранней диагностикой и своевременной патогенетически обоснованной коррекцией нарушений менструальной функции, а также повышение устойчивости организма к эмоциональному и физическому стрессу за счет использования немедикаментозных оздоровительных методов, в том числе светотерапии, снижающей уровень мелатонина, будет способствовать сохранению репродуктивного здоровья будущей женщины-матери.

\section{ВЫВОДЫ}

1. Становление менструальной функции у девочек-подростков обусловлено созреванием гипоталамо-гипофизарной системы, связанным со снижением уровня мелатонина и серотонина.

2. Определение уровня мелатонина у девочек-подростков с задержкой становления менструальной функции может иметь диагностическое и прогностическое значение, так как запаздывание возрастного снижения уровня мелатонина может быть одной из основных причин задержки становления менструальной функции.

3. Нарушения центральных механизмов регуляции менструальной функции у девочек могут быть обусловлены в определенной мере влиянием хронического стресса, связанного с высокими физическими и эмоциональными нагрузками девочек-школьниц в сочетании с неблагоприятными экологическими условиями жизни в большом промышленном городе.

Список литературы в количестве 8 источников представлен на сайте www.reproduct-endo.com.ua 